\title{
Simulation Analysis of the Impact of Unbalanced Three-Phase Load on Distribution Transformer's Outlet Voltage
}

\author{
Zeyang Tang ${ }^{1 *}$, Li Wan ${ }^{1}$, Kan Cao ${ }^{1}$, Yuze Rao ${ }^{1}$, Junhui Xin ${ }^{1}$ and Kunpeng Zhou ${ }^{1}$ \\ ${ }^{1}$ State Grid Hubei Electirc Power Research Insititue, Wuhan Hubei 430077, China
}

\begin{abstract}
In order to study the influence of unbalanced threephase load on distribution transformer's outlet voltage, the ATPEMTP simulation model has been built. Distribution transformer's outlet voltage under different load parameters has been researched. The simulation results show that active and reactive power have influence on distribution transformer's outlet voltage simultaneously. The unbalanced three-phase load will cause the unbalance of distribution transformer's outlet three-phase voltage. The simulation results agree well with the measured results. It's actually not the case that the heavier the load, the lower the phase voltage while the lighter the load, the higher the phase voltage. When the three-phase load is unbalanced, there are 6 kinds of relationship between the distribution transformer's outlet three phase voltage.
\end{abstract}

Keywords-three-phase load; unbalanced; distribution transformer's outlet voltage; reactive power; ATP-EMTP

\section{INTRODUCTION}

When the three-phase load is unbalanced, on one hand, due to the low voltage side is three-phase four wire system, the neutral line will have unbalanced current flows through. Transformer loss and the line loss will increase when transformer is in the asymmetrical operation state ${ }^{[1-2]}$. Some scholars have carried out control measures about three-phase unbalanced load, including manual off-line load adjustment ${ }^{[3]}$, install compensation device ${ }^{[4]}$, three-phase load balancing based on fast phase selection ${ }^{[5]}$, online automatic phase change [6], three-phase unbalanced load real-time control ${ }^{[7-8]}$, install phase switch $^{[9]}$. On the other hand, three-phase unbalanced load will lead to three-phase voltage imbalance, some researchers have carried out relevant research. Yin Jiming ${ }^{[10]}$ studied threephase voltage unbalance from the structural, functional and fault factors, Qian Shaofeng ${ }^{[11]}$ analyzed the impact of unbalanced load on YYN0 transformer by symmetrical component method. Zhou Yang ${ }^{[12]}$ studied the influence of three-phase unbalanced load on the low voltage side. However, the analysis focus on the offset of load side neutral point, the shift of high voltage side neutral point is not studied. The conclusion of the study did not reflect the impact of three phase unbalanced load on transformer's outlet voltage, and only considered the three-phase active power while did not take into account the reactive power. Therefore, many researchers believe that when the three-phase load is unbalanced, the heavier the load, the lower the phase voltage while the lighter the load, the higher the phase voltage. However, according to the data of PMS distribution network operation and management control module, the active power of phase $A$ is $41.1 \mathrm{~kW}$ which is the maximum of the three phases, but the transformer's outlet voltage of phase A is not the lowest. In order to explain this phenomenon, this paper establishes a ATP-EMTP simulation model to study the transformer's outlet voltage under different load parameters. The possible relationships of three-phase voltage under three-phase unbalanced load condition have also been summarized.

\section{Simulation MODEL}

It was shown in FIGURE I that the ATP-EMTP simulation model has been built to investigate the influence of unbalanced three-phase load on distribution transformer's outlet voltage. The simulation model included power source, transformer, load, low line, and neutral conductor. The circuit from power source to transformer was not included, and the concentrated load was employed.

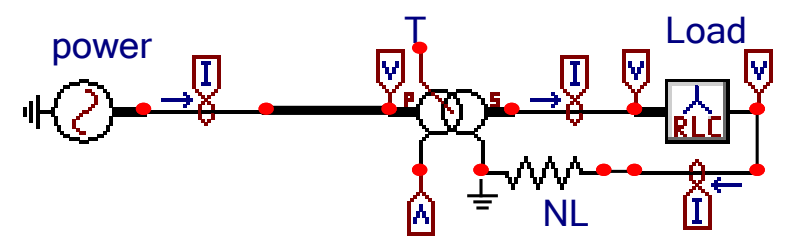

FIGURE I. SIMULATION MODEL

1) Power source parameters

Making the $10 \mathrm{kV}$ external circuit equivalent to one power source. The amplitude (Um) of the single phase alternating current from power source was:

$$
U_{\mathrm{m}}=\frac{\sqrt{2}}{\sqrt{3}} \times 10 \mathrm{kV}=8165 \mathrm{~V}
$$

\section{2) Transformer parameters}

The wiring form of distribution transformer winding in the simulation model was YYN0 connection. The nominal voltage (UN) of $10 \mathrm{kV}$ distributing line was $10 \mathrm{kV}$ while the frequency (f) was $50 \mathrm{~Hz}$. When the transformer capacity (SN) was 100kVA and its short circuit impedance percent (Vs) was 4\%, the reactance of high-pressure side could be figured out: 


$$
X_{\mathrm{T}}=V_{\mathrm{s}} \frac{U_{\mathrm{N}}^{2}}{S_{\mathrm{N}}} \times 10^{3}=40 \Omega
$$

The winding inductance of high-pressure side was

$$
L_{\mathrm{H}}=\frac{X_{\mathrm{T}}}{2 \pi f}=127.3 \mathrm{mH}
$$

The transformer excitation resistance (Rm) was valued $1000 \Omega$ and the zero sequence excitation resistance (R0) was valued $2 \Omega$, while the distribution gear was set as $9.5 \mathrm{kV}$.

\section{3) Load parameter}

In the simulation model, one resistance RLoad and one inductance LLoad were in parallel to simulate the load, and the load voltage ULoad was $220 \mathrm{~V}$. For instance, when the active power (P) of load was $10 \mathrm{~kW}$ and the reactive power (Q) of load was $4.8 \mathrm{kVar}$, the calculation was as follows:

$$
\begin{gathered}
R_{\text {Load }}=\frac{U_{\text {Load }}^{2}}{P}=4.84 \Omega \\
L_{\text {Load }}=\frac{U_{\text {Load }}^{2}}{Q} \frac{1}{2 \pi f}=32.09 \mathrm{mH}
\end{gathered}
$$

\section{4) Line parameter}

The conductor type of low line and neutral conductor was LGJ-150 with the length was $0.5 \mathrm{~km}$, the resistance per unit length was $0.21 \Omega / \mathrm{km}$ and the reactance per unit length was $0.39 \Omega / \mathrm{km}$.

\section{ANALYSIS OF SIMULATION RESULT}

\section{A. Load Influence}

To investigate the influence of load on distribution transformer's outlet voltage, the simulation was conducted by using 5 groups of load parameters (TABLE I). In parameter set 1 , the three-phase active power and reactive power were both the same. In parameter set 2 , the three-phase active power was the same while the reactive power was different. In parameter set 3 to 5, the three-phase active power and reactive power were both different.

When the wiring form of transformer winding was YYN0 connection, the simulation results of different load parameters can be seen from TABLE II. It was indicated from the simulation results that the active power and reactive power of three-phase load in parameter set 1 were both the same, and the distribution transformer's outlet voltage was symmetry. The three-phase voltages were both $233.6 \mathrm{~V}$ and the neutral point of distribution transformer's outlet voltage side was not in excursion. The three-phase load active power in parameter set 2 was the same, but the reactive power was different. The distribution transformer's outlet voltage was dissymmetry, among which the lowest Phase A voltage was $214.8 \mathrm{~V}$, the highest Phase C voltage was $254.9 \mathrm{~V}$, the neutral point of distribution transformer's outlet voltage was $423.6 \mathrm{~V}$, and the lag Phase A voltage was 45.7 degree. The comparison with the simulation results of parameter 1 and 2 showed that distribution transformer's outlet voltage was not only influenced by load active power but also load reactive power.

\section{TABLE I. LOAD PARAMETERS IN SIMULATION MODEL}

\begin{tabular}{cccccc}
\hline $\begin{array}{c}\text { Parameter } \\
\text { set }\end{array}$ & Phase & $\begin{array}{c}\text { Active } \\
\text { power/kW }\end{array}$ & $\begin{array}{c}\text { Reactive } \\
\text { power/kVar }\end{array}$ & $\begin{array}{c}\text { Power } \\
\text { factor }\end{array}$ & $\begin{array}{c}\text { Apparent } \\
\text { power/kVA }\end{array}$ \\
\hline \multirow{2}{*}{1} & A & 25.0 & 15.0 & 0.86 & 29.2 \\
& B & 25.0 & 15.0 & 0.86 & 29.2 \\
& C & 25.0 & 15.0 & 0.86 & 29.2 \\
2 & A & 25.0 & 15.0 & 0.86 & 29.2 \\
& B & 25.0 & 6.0 & 0.97 & 25.7 \\
& C & 25.0 & 3.0 & 0.99 & 25.2 \\
& A & 40.5 & 15.0 & 0.94 & 43.2 \\
3 & B & 32.9 & 6.0 & 0.98 & 33.4 \\
& C & 25.0 & 3.0 & 0.99 & 25.2 \\
4 & A & 41.1 & 10.0 & 0.97 & 42.3 \\
& B & 28.8 & 12.0 & 0.92 & 31.2 \\
& C & 7.1 & 1.0 & 0.99 & 7.2 \\
5 & A & 40.5 & 2.0 & 1.00 & 40.5 \\
& B & 32.9 & 11.0 & 0.95 & 34.7 \\
\hline
\end{tabular}

The comparison with parameter set 3 and 5 indicated that the active power in both parameter sets was the same. The highest Phase A active power was $40.5 \mathrm{~W}$ while the lowest Phase $\mathrm{C}$ active power was $25 \mathrm{~kW}$, but the reactive power of these two parameter sets was different. The comparison with the simulation results of two parameter sets showed that the lowest Phase A voltage of the distribution transformer's outlet voltage in parameter set 3 was $213.3 \mathrm{~V}$ and the highest Phase C voltage was $257.8 \mathrm{~V}$. The neutral point of distribution transformer's outlet voltage was $465.9 \mathrm{~V}$, and the lag Phase A voltage was 59 degree. The highest Phase A voltage of the distribution transformer's outlet voltage in parameter set 5 was 254.7V, and the lowest Phase C voltage was 212.7V. The neutral point of distribution transformer's outlet voltage was 453.6V, and the lag Phase A voltage was 214 degree. The apparent power of the two parameter sets was both the highest in Phase A and lowest in Phase C. From the above analysis, it can be concluded that when the three-phase load was unbalanced, it wasn't always the fact that the Phase A with the highest power had the lowest voltage while the Phase A with the lowest power had the highest voltage.

The simulation results of the parameter set 4 indicated that the lowest Phase B voltage of distribution transformer's outlet voltage was $204.6 \mathrm{~V}$, and the highest Phase C voltage was 255.9V. The neutral point of distribution transformer's outlet voltage high voltage was $571.3 \mathrm{~V}$, and the lag Phase A voltage was 116.8 degree. TABLE III showed the comparison of simulation results of parameter set 4 and the measured data, and the results were identical. These results can well explain the phenomenon that the active power was the highest but the voltage wasn't the lowest. 
TABLE II. SIMULATION RESULTS UNDER DIFFERENT LOAD PARAMETERS (TRANSFORMER WINDING IS YYNO)

\begin{tabular}{cccccc}
\hline \multirow{2}{*}{$\begin{array}{c}\text { Parameter } \\
\text { set }\end{array}$} & \multicolumn{2}{c}{ Voltage effective value/V } & \multicolumn{2}{c}{ Neutral point of high voltage } \\
side
\end{tabular}

TABLE III. COMPARISON OF SIMULATION RESULTS AND MEASURED DATA

\begin{tabular}{ccccc}
\hline \multirow{2}{*}{ Phase } & \multicolumn{2}{c}{ Simulation (parameter set 4) } & \multicolumn{2}{c}{$\begin{array}{c}\text { Actual measurement (27th } \\
\text { January, 17:15) }\end{array}$} \\
\cline { 2 - 5 } & Active power/kW & Voltage/ & Active power/kW & Voltage/ \\
\hline A & 41.1 & 237.8 & 41.1 & 234.9 \\
B & 28.8 & 204.6 & 28.9 & 201.4 \\
C & 7.1 & 255.9 & 7.1 & 254.8 \\
\hline
\end{tabular}

B. Analysis on the Neutral Point Deviation Position of Distribution Transformer's Outlet Voltage Side

TABLE II showed the comparison with simulation results of parameter set 3 and 5 . The voltage effective values of the neutral point of the distribution transformer's outlet voltage side were very close, but the angles of the lag Phase A voltage were very different. The distribution transformer's outlet threephase voltage from the simulation of parameter set 3 and 5 were quite different. According to the angle of the lag Phase A voltage from the simulation of parameter set 3 and 5 , the position after the neutral point migration was drawn in FIGURE II.

In FIGURE II(a), $\mathrm{N}$ was the neutral point of the distribution transformer's outlet voltage when the three-phase load was symmetry. $\mathrm{N}^{\prime}$ was the neutral point of the distribution transform high voltage when the three-phase load was dissymmetry. NA, NB, NC represented the three-phase voltage of A, B, C respectively when the three-phase load was symmetry. N'A, N'B, N'C represented the three-phase voltage of $\mathrm{A}, \mathrm{B}, \mathrm{C}$ respectively when the three-phase load was dissymmetry. OC was the angular bisector of $\angle A C B$. It can be easily known from the geometrical relationship that when $\mathrm{N}^{\prime}$ fell over within the scope of <ANO, then $\mathrm{N}^{\prime} \mathrm{B}>\mathrm{N}^{\prime} \mathrm{A}$; and $\mathrm{N}^{\prime}$ was located underneath MA which was the angular bisector of $<$ CAB. Similarly, N'C $>N^{\prime} B$. To sum up, N'C $>N^{\prime} B>N^{\prime} A$, that is $\mathrm{UA}<\mathrm{UB}<\mathrm{UC}$. In the same way, similar analysis can be conducted on the simulation results from parameter set 4 and 5 .

Based on the above analysis, when the three-phase load was unbalanced, the neutral point displacement of the transformer's outlet voltage can be divided into six intervals called D1-D6. The value relationship of the distribution transformer's threephase voltage from each section was different. TABLE IV showed the relationship of transformer's outlet three phase voltage in six intervals.
TABLE IV. THE RELATIONSHIP OF TRANSFORMER'S OUTLET THREE PHASE VOLTAGE IN DIFFERENT INTERVALS

\begin{tabular}{ccc}
\hline Interval & Angle range/degree & Value relationship \\
\hline D1 & $(0,60)$ & $\mathrm{UA}<\mathrm{UB}<\mathrm{UC}$ \\
D2 & $(60,120)$ & $\mathrm{UB}<\mathrm{UA}<\mathrm{UC}$ \\
D3 & $(120,180)$ & $\mathrm{UB}<\mathrm{UC}<\mathrm{UA}$ \\
D4 & $(180,240)$ & $\mathrm{UC}<\mathrm{UB}<\mathrm{UA}$ \\
D5 & $(240,300)$ & $\mathrm{UC}<\mathrm{UA}<\mathrm{UB}$ \\
D6 & $(300,360)$ & $\mathrm{UA}<\mathrm{UC}<\mathrm{UB}$ \\
\hline
\end{tabular}

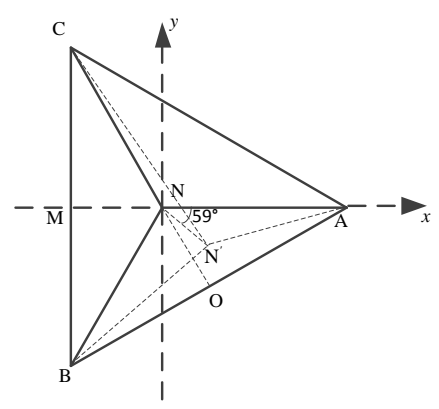

(A) PARAMETER SET 3

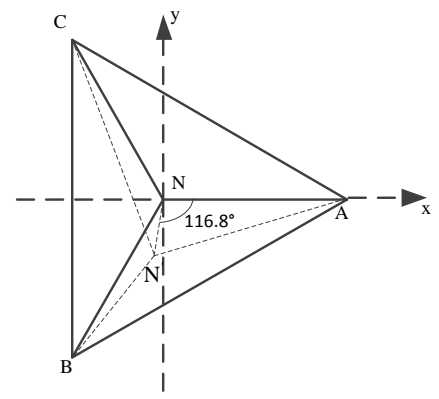

(B) PARAMETER SET 4

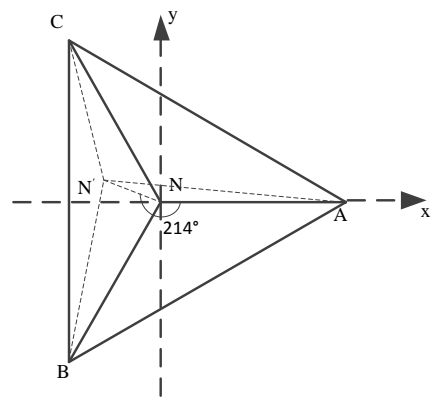

(C) PARAMETER SET 5

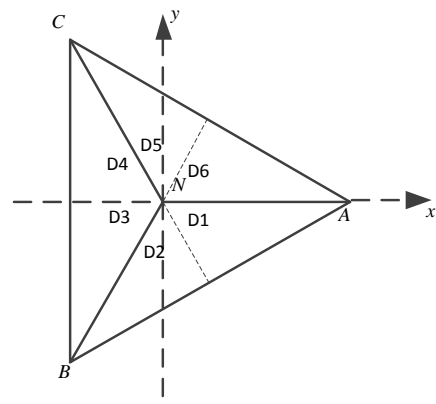

(D) REGIONAL DIVISION

FIGURE II. SCHEMATIC DIAGRAM OF NEUTRAL POINT DEVIATION OF TRANSFORMER'S HIGH VOLTAGE SIDE 


\section{CONCLUSION}

By establishing the ATP-EMTP simulation model, the influence of load on the distribution transformer's outlet voltage was investigated. The conclusions were as follows:

1) The simulation results indicated that the unbalanced three-phase load caused the unbalance of distribution transformer's outlet three-phase voltage. The active and reactive power have influence on distribution transformer's outlet voltage simultaneously. It's actually not the case that the heavier the load, the lower the phase voltage while the lighter the load, the higher the phase voltage.

2) The results of simulation and actual measurement were identical, which can well explain the phenomenon that some phase with the highest active power had the lowest voltage.

3) When the three-phase load is unbalanced, there are 6 kinds of relationship between the distribution transformer's outlet three-phase voltage.

\section{ACKNOWLEDGEMENT}

This paper is supported by project of State Grid of Hubei power supply company, No $52153216001 \mathrm{H}$.

\section{REFERENCES}

[1] Wang Biao, Zheng Tao, Ni Bin, et al. Theoretical line loss calculation of rural low-voltage distribution networks considering unbalanced three-phase loads[J]. Journal of electric power science and technology, 2013, 28(1):81-85.

[2] Jiang Hao, Wang Miao. Analysis on the influence of unbalanced threephase loads on LV line loss[J]. Distribution and utilization, 2008, 25(3):68-70.

[3] Zhang Ming, Xie Shanshan, Luo Yunfeng. Optimization model of the three-phase load imbalance in low voltage distribution network. Journal of Wuhan university of science and technology, 2015, 38(1):59-62.

[4] Li Haifeng, Zan Tao, Wu Xuanguang, et al. Governance of unbalanced three-phase load of distribution transformer[J]. Rural electrification, 2012(s1):187-187.

[5] Xiang Ci, Liu Zhanjie, Yu Wei. Adjust of three-phase load based on rapid phase selection[J]. Rural electrification, 2015(11):11-13.

[6] Xin Yechun, Li Guoqing, Wang Chaobin. Compensation control of reactive power and three-phase unbalance load based on the method of sequence component[J]. Power system protection and control, 2014(14):72-78.

[7] Fang Hengfu, Duan Xiangjun, Wang Wei. Governance method of unbalanced three-phase load of distribution transformer[J]. China electric power enterprise management, 2015(4X):94-95.

[8] Fang Hengfu, Sheng Wanxin, Wang Jinli, et al. Research on the method for real-time online control of three-phase unbalanced load in distribution area[J]. Proceedings of the CSEE, 2015, 35(9):2185-2193.

[9] Zhang Zhengkai, Zhang Yuande, Shi Liang, et al. The governance scheme of three-phase unbalanced load management for intelligent distribution transformer. Power DSM, 2016(1):49-52.

[10] Yin Jiming. Analysis of unbalance of $10 \mathrm{kV}$ distribution transformer's three-phase voltage[J]. Telecom world, 2016(9):162-163.

[11] Qian Shaofeng, Chen Guoqi, Zhou Liang, et al. Investigation for practical application of YYN0 type power transformers[J].Electrical technology, 2014(5):123-125.

[12] Zhou Yang, Feng Jun, Li Liang. The impact and countermeasure of unbalanced three-phase load on distribution transformer's low voltage side[J]. Electrical Engineering, 2013(2):7. 